\section{RMD Open}

Rheumatic \& Musculoskeletal Diseases

\title{
Gout, Hyperuricaemia and Crystal- Associated Disease Network (G-CAN) common language definition of gout
}

Rachel Murdoch (D) ,' Michael J Barry, ${ }^{2}$ Hyon K Choi, ${ }^{3}$ Daniel Hernandez, ${ }^{4}$ Brianne Johnsen, ${ }^{3}$ Manuel Labrador, ${ }^{5}$ Susan Reid, ${ }^{1}$ Jasvinder A Singh (1) ,,7 Robert Terkeltaub, ${ }^{8}$ Janitzia Vázquez Mellado, ${ }^{5}$ Nicola Dalbeth (i) ${ }^{1}$

To cite: Murdoch R, Barry MJ, Choi HK, et al. Gout, Hyperuricaemia and CrystalAssociated Disease Network (G-CAN) common language definition of gout. RMD Open 2021;7:e001623. doi:10.1136/ rmdopen-2021-001623

Received 8 February 2021 Revised 23 March 2021 Accepted 2 April 2021
Check for updates

(C) Author(s) (or their employer(s)) 2021. Re-use permitted under CC BY-NC. No commercial re-use. See rights and permissions. Published by BMJ.

For numbered affiliations see end of article.

Correspondence to Dr Nicola Dalbeth; n.dalbeth@auckland.ac.nz

\section{ABSTRACT}

Objective To develop a Gout, Hyperuricaemia and CrystalAssociated Disease Network (G-CAN) common language definition of gout, with the goal of increasing public understanding and awareness, and ensure consistent and understandable messages about gout.

Methods A G-CAN working group that included patients, physicians and nongovernmental organisation (NGO) representatives was formed to develop a common language definition of gout for use with the public, media, healthcare providers and stakeholders. A literature search and interviews with patients, healthcare workers and stakeholders informed development of the definition. Following consultation with G-CAN members and partners, the definition was endorsed by the G-CAN board.

Results The G-CAN common language definition of gout describes the epidemiology, pathophysiology, symptoms and impact, risk factors, comorbidities, management and healthcare and workforce considerations. Detailed information is provided to support the content of the definition. After the publication of the English-language version, the definition will be available for translation into other languages by G-CAN members.

Conclusion G-CAN has developed a concise and easily understandable statement describing gout in language that can be used in conversations with the lay public, media, NGOs, funders, healthcare providers and other stakeholders.

\section{INTRODUCTION}

Gout is the most common form of inflammatory arthritis affecting adults. ${ }^{1}$ Despite its high prevalence and impact, gout is understudied and often undertreated. ${ }^{2-4}$ One mechanism to increase public understanding and awareness, and ensure consistent and understandable messages about a disease, is development of an agreed common language definition. For example, the European League Against Rheumatism (EULAR) and American College of Rheumatology (ACR) developed a common language definition of rheumatic and musculoskeletal diseases (RMDs) to allow

\section{Key messages}

What is already known about this subject?

- Despite its high prevalence and impact, gout is understudied and often undertreated.

What does this study add?

- The common language definition of gout encompasses key information relevant to gout as determined by a review of the literature, interviews with patients, healthcare workers and stakeholders and consultation with crystal-associated disease network members and stakeholders.

How might this impact on clinical practice or future developments?

- This common language definition of gout has been developed to promote consistent, accurate and informative discussion about gout with the public, healthcare workers and stakeholders.

consistent use when describing these conditions. ${ }^{5}$ This short general definition included a general description of RMDs, the causes of disease, the experience of people with the disease and the impact of RMDs.

The Gout, Hyperuricaemia and CrystalAssociated Disease Network (G-CAN) is an international, multidisciplinary collaboration, dedicated to advancing the crystal deposition-associated disorders. In 2019, G-CAN convened a working group to develop a common language definition of gout; a concise and easily understandable statement describing gout in language can be used in conversations with the lay public, media, nongovernmental organisations (NGOs), funders, healthcare providers and other stakeholders. This work followed G-CAN consensus definitions of the disease elements and disease states of gout for technical communications. ${ }^{67}$ Herein, we describe 


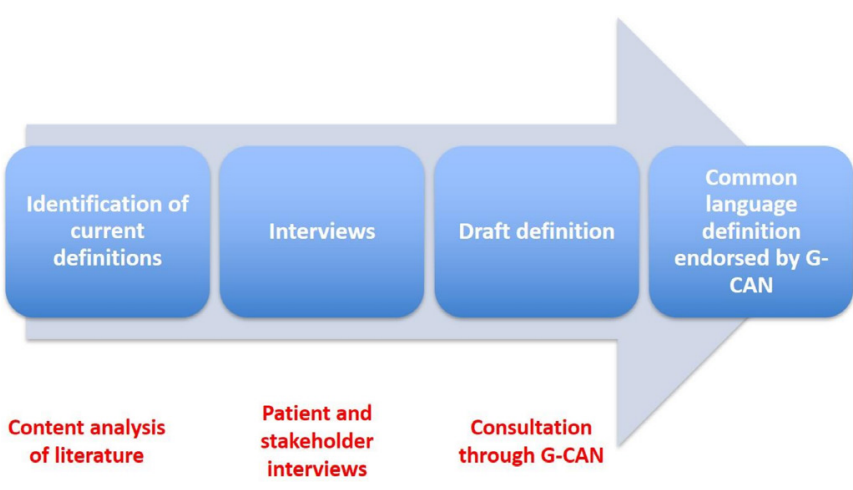

Figure 1 Development of the Gout, Hyperuricaemia and Crystal-Associated Disease Network (G-CAN) common language definition of gout.

the development and outcome of the G-CAN common language definition of gout project.

\section{METHODS}

The components and flow of the project are shown in figure 1. The G-CAN working group included patient representatives, a health literacy expert, an NGO representative, a primary care physician, a physician assistant and rheumatologists. A literature review of key aspects of epidemiology, pathophysiology, symptoms, management and impact of gout, including grey literature sources, and interviews with patients, stakeholders and healthcare workers were undertaken to inform the development of the common language definition.

\section{Scope of project}

Working group members met to agree on the scope of the common language definition and literature review. It was agreed that the common language definition would be a concise statement written in language understandable to a broad audience and that G-CAN recommended nomenclature, such as 'gout flare' would be used. ${ }^{6}$ It was decided that the final definition would be available for translation into different languages by G-CAN members. The definition will be reviewed and updated as new evidence emerges.

\section{Content analysis of literature}

A literature search was undertaken to extract the major aspects of gout described in the literature and review articles about gout from major general medical journals and articles from the grey literature databases. Using the search term 'gout', the databases were searched for articles related to the epidemiology, pathophysiology, comorbidities, symptoms, management and impact on patients of gout. Review articles and governmental and NGO reports, documents or guidelines were included. Relevant information was extracted from 93 articles and the key messages for each category (pathophysiology, epidemiology, symptoms, comorbid disorders, diagnostic investigations, management and impact on patients and community) were compiled.
The main factors relating to pathophysiology that were identified in the literature review were that hyperuricaemia, formation of monosodium urate crystals, inflammation and underexcretion and overproduction of urate contribute to the development of gout. The main points related to epidemiology included that gout is common and increasing in prevalence. The main symptoms described in the literature were pain and swelling, and common comorbid disorders were cardiovascular disease, chronic kidney disease, diabetes and hypertension. Management strategies described included uratelowering therapy and anti-inflammatory medications. The impact of gout included the effects on employment and quality of life, increased healthcare use and impact on physical well-being.

Major articles identified through MEDLINE and recent guidelines relating to the topics of pathophysiology, symptoms, impact on patients, risk factors, comorbidities, management and health and workforce considerations were also summarised to support statements within the definition.

\section{Patient and stakeholder interviews}

A total of 19 patients, healthcare workers and stakeholders were interviewed to identify important messages for inclusion in the definition. Patients with gout $(n=7)$ were identified through a clinical research centre. Healthcare workers $(\mathrm{n}=7$, pharmacist, nutritionist, general practitioner, internist, rheumatologist, nurse and podiatrist) and stakeholders $(\mathrm{n}=5$, from an NGO providing patient support and education, a funding body and a government organisation) were identified through professional networks. These individuals were invited to take part in interviews about what should be included in a definition of gout. Participants were asked a set of questions about their experience of gout, what would be important for people to know about gout, how gout impacts on patients and the community and what challenges there are in the management of gout. The interviews were transcribed by the research fellow and analysed using NVivo software to identify the main themes and messages. Interviews were continued until data saturation was reached.

Key messages from the interviews were reviewed by the working group to assist with developing the definition. Key messages patients wanted to communicate about gout included the severity of pain, that it is controllable with treatment, and that it can be related to diet. The effect on ability to work and the importance of receiving appropriate treatment were also emphasised. Healthcare workers and stakeholders identified that it was important to know that gout is related to genetic factors, that recurrent gout flares can be prevented with long-term urate-lowering therapy, that people should not be blamed for having gout, and that the relationship between healthcare provider and patient is important. 
Box 1 The Gout, Hyperuricaemia and Crystal-Associated Disease Network common language definition of gout

Gout is a common condition caused by high levels of urate (also known as uric acid) in the body. Having too much urate causes crystals to form in the joints that can result in inflammation and damage. People are usually diagnosed with gout when they have an attack of a very painful arthritis, which can cause difficulty sleeping, walking and working. This is called a gout flare. For most people, gout happens when the kidneys do not remove enough urate from the body, with genetic make-up playing a critical role for some groups. Gout often occurs alongside other health problems such as high blood pressure, heart disease, diabetes and kidney disease, with shared risk factors including being overweight, diet and alcohol consumption. Gout flares are treated in the short term with anti-inflammatory medicines. Long-term daily medicines such as allopurinol decrease the amount of urate in the body and dissolve the urate crystals, resulting ultimately in prevention of gout flares and joint damage. Healthcare workers such as doctors, nurses and pharmacists can help people with gout understand the condition, reduce stigma and work with them to make management choices.

\section{Consultation through G-CAN}

The results of the literature review and interviews were circulated to all working group members who met on two further occasions by teleconference to agree on a draft definition to be distributed for consultation. This definition was circulated for consultation to all G-CAN members and partners. It was then modified based on the feedback. The subsequent definition was circulated and agreed by the working group, reviewed by patients and lay readers for clarity and sent to the G-CAN board for endorsement.

\section{RESULTS}

The key messages from the literature review, interviews, discussion of the working group and feedback from G-CAN members and partners are incorporated in the final definition (box 1).

The following commentary provides detailed justification for the text included in the G-CAN common language definition of gout.

\section{Epidemiology}

Gout is a common disease with increasing incidence and prevalence, particularly in Western or westernising countries, paralleling the obesity epidemic over recent decades. ${ }^{8-11}$ There are currently an estimated 41 million people worldwide with gout. ${ }^{10}$ It is the most common form of inflammatory arthritis, ${ }^{12}$ estimated to affect about $4 \%$ of the population in the USA, ${ }^{13} 2 \%-3 \%$ in the ${ }^{14} \mathrm{UK}$ and $0.9 \%-2.5 \%$ in Europe. ${ }^{15}$ It is more common in men, with a prevalence of $5.2 \%$ in men and $2.7 \%$ in women. ${ }^{13}$ This prevalence increased with age to $9.3 \%$ of US adults over 60 years, although it can also affect young men. ${ }^{16}{ }^{17}$ Gout is rare in women before menopause and does not usually affect children. It is more common in some ethnic groups such as Māori, Pacific Peoples and
Taiwanese Indigenous Peoples. ${ }^{18} 19$ In Aotearoa/New Zealand, Māori and Pacific peoples have 2-3 times the prevalence of gout as non-Māori, non-Pacific peoples ${ }^{20}$ and the prevalence of gout in Taiwanese Indigenous men and women is $15.2 \%$ and $4.8 \%$, respectively, compared with $0.3 \%$ in Taiwanese non-Indigenous people. ${ }^{21}$

\section{Pathophysiology}

Hyperuricaemia and deposition of monosodium urate crystals are the key pathophysiological mechanisms leading to the development of gout. Disease stages include asymptomatic hyperuricaemia, asymptomatic deposition of monosodium urate crystals, monosodium urate crystal deposition with gout flares and intercritical gout, and usually later in the disease course (in the absence of urate-lowering therapy), chronic gouty arthritis, tophus deposition and gouty bone erosion. ${ }^{22}$

Urate is produced mainly in the liver and intestinal cells. ${ }^{23}$ About two-thirds is excreted by the kidneys and the remainder in the gut. ${ }^{24}$ When the level of urate is above the saturation point of $6.8 \mathrm{mg} / \mathrm{dL}(408 \mu \mathrm{mol} / \mathrm{L})$, monosodium urate crystals form at $\mathrm{pH} 7.0$ and temperature $37^{\circ} \mathrm{C} .{ }^{25}$

A gout flare arises when immune cells interact with the monosodium urate crystals, triggering an episode of acute inflammation. The release of the cytokine interleukin (IL) $-1 \beta$ by immune cells is particularly important in driving inflammation in the gout flare. ${ }^{26}$ Many other proinflammatory mediators also contribute to the gout flare.

Gout is characterised by repeated gout flares with intercritical periods during which the patient is asymptomatic but remains hyperuricaemic with risk of further gout flares. ${ }^{22}$ Monosodium urate crystals can be found in the synovial fluid during the intercritical period. ${ }^{27}$ If the hyperuricaemia responsible for gout is untreated, subcutaneous tophi can develop; these nodules are discrete collection of monosodium urate crystals with associated tissue response. ${ }^{6}$ Tophi can lead to bone erosion and cartilage damage. ${ }^{28}$

\section{Symptoms and impact}

The key symptom of the gout flare is severe joint pain. Qualitative studies of patients with gout show that pain is an important symptom. ${ }^{29}$ Other symptoms of a gout flare are joint swelling, redness and heat. ${ }^{30} 31$ Typically, the symptoms develop quickly, often starting at night, peak within 24 hours and resolve within 1-2 weeks. ${ }^{32}$

Patients commonly experience difficulty mobilising during a gout flare ${ }^{33}$ Sleep disorders and daytime sleepiness are also frequently seen. ${ }^{34-37}$ Work absences are higher in people with gout; a Swedish population-based cohort study reported an average work absentee rate over 3 years of $22 \%$ in people with gout compared with $14 \%$ of matched population controls. ${ }^{38}$ Gout also has an impact on family and wider community. Family members may be absent from work or education to care for those with gout. ${ }^{29}$ There is also a financial impact on the family and 
on businesses when individuals with gout are absent from work or unemployed, with annual loss of income for patients with severe gout estimated to be up to US $\$ 4341$ per year. ${ }^{39}$

\section{Risk factors}

Majority of hyperuricaemia is the result of reduced renal clearance of urate,${ }^{40}$ which can be due to sex, genetic variations, obesity, insulin resistance, medications and kidney disease. ${ }^{41-48}$ It can also be caused by overproduction due to high dietary purines or increased cell turnover ${ }^{490}$ and intestinal extrarenal underexcretion. ${ }^{1151}$

Genetics plays a major role in hyperuricaemia. ${ }^{52} 53$ Multiple genes have been identified, which contribute to risk of hyperuricaemia, most of which are involved in urate transport. ${ }^{54}$ Genome-wide association analysis has identified multiple loci associated with gout including ABCG2, SLC2A9, SLC22A11, GCKR and SLC17A1. ${ }^{41} \mathrm{~A}$ missense single-nucleotide polymorphism in $A B C G 2$, which is expressed in the gut, is associated with urate concentration and risk of gout. ${ }^{55}$

Renal underexcretion of urate is a major mechanism of hyperuricaemia. This can be genetic, mediated by variants of urate transporters such as SLC2A9 and SLC22A11, but may also occur in the context of acquired kidney disease. ${ }^{47}$

Being overweight or obese is the strongest modifiable risk factor for hyperuricaemia and gout. Obesity raises the serum urate level, through both lowering renal urate excretion and increasing urate production. 47485657 Mendelian randomisation studies have shown obesity to be causally associated with serum urate levels, ${ }^{58-60}$ and weight loss through bariatric surgery ${ }^{61-63}$ or dietary intervention leads to reductions in serum urate levels. ${ }^{64-66} \mathrm{~A}$ recent Global Burden of Disease analyses of 195 countries and territories between 1990 and 2017 found that high body mass index accounted for $53.4 \%$ and $48.6 \%$ of the years lived with disability for gout in high-income North America and Australasia. ${ }^{10}$ Early adult obesity in women was associated with a 2.8-fold increased risk of gout compared with nonobese women in a study using data from the Atherosclerosis Risk in Communities (ARIC) study. ${ }^{67}$

Higher meat intake (particularly red meat), seafood intake and alcohol consumption are associated with an increased risk of hyperuricaemia, ${ }^{68-70}$ incident gout ${ }^{7172}$ and recurrent gout flares ${ }^{73}$ partly because their high purine content raises urate levels, as demonstrated by short-term metabolic experiments of purine loading in animals and humans. ${ }^{75}$ Healthy cardiometabolic diets such as the Mediterranean or Dietary Approaches to Stop Hypertension diet lowered serum urate in secondary analyses of clinical trials ${ }^{64-79}$ and are associated with a lower risk of incident gout, whereas the Western diet is associated with a higher risk. ${ }^{80}$

\section{Comorbidities}

Gout coexists often with metabolic syndrome $(63 \%)^{81}$ and is associated with cardiometabolic-renal comorbidities ${ }^{82}$ and premature mortality. ${ }^{83}$ In the USA, $74 \%$ of those with gout had hypertension, $71 \%$ chronic kidney disease stage $\geq 2,53 \%$ obesity, $26 \%$ diabetes, $14 \%$ myocardial infarction and $10 \%$ stroke. ${ }^{82}$ It is associated with increased risk of nephrolithiasis (occurring in approximately $24 \%$ of patients with gout). ${ }^{82} 84$

\section{Management}

Treatment of a gout flare should be commenced as soon as possible, with nonsteroidal anti-inflammatory drugs, colchicine or glucocorticoids being first-line options for treatment. ${ }^{85}$ An open-label randomised trial comparing low-dose colchicine $500 \mathrm{mg}$ three times per day for 4 days with naproxen $750 \mathrm{mg}$ immediately, then $250 \mathrm{mg}$ every 8 hours for 7 days found that there was no difference between the two groups in terms of pain intensity over 7 days although side effects were more common in the colchicine group, mainly diarrhoea and headache. ${ }^{86}$ Another randomised trial comparing oral prednisone and naproxen for monoarticular gout found that either prednisolone $35 \mathrm{mg}$ once a day or naproxen $500 \mathrm{mg}$ two times a day for 5 days were equally effective, and adverse effects were similar between groups ${ }^{33}$ Symptomatic treatment for a gout flare includes immobilisation of the joint and use of cold packs. ${ }^{87}$ Anti-IL-1 $\beta$ monoclonal antibodies have also been found to be effective for relief of gout flares ${ }^{88}$ and are generally recommended for patients experiencing gout flares where other drugs have caused side effects or were ineffective. ${ }^{85}$

Long-term use of urate-lowering therapy leads to crystal dissolution, ${ }^{89} 90$ resulting in suppression of gout flares, ${ }^{91} 92$ regression of tophi ${ }^{92}$ and prevention of progressive joint damage. ${ }^{93}$ Rheumatology societies strongly recommend urate-lowering therapy for patients with tophi, evidence of radiographic damage attributable to gout or frequent gout flares. ${ }^{85} 94$ Urate-lowering therapy may also have benefit earlier in the disease course. ${ }^{91}$ Allopurinol is the preferred and most commonly prescribed first-line uratelowering therapy. ${ }^{85} 95$ Second-line treatments include febuxostat, another xanthine oxidase inhibitor, probenecid, a uricosuric agent and pegloticase, a recombinant uricase administered intravenously.

A treat-to-target serum urate approach is recommended by the ACR guidelines ${ }^{85}$ and EULAR recommendations. ${ }^{94}$ Serum urate monitoring allows the dose of medication to be titrated to a target serum urate of below $6 \mathrm{mg} / \mathrm{dL}$ (360 $\mu \mathrm{mol} / \mathrm{L}$ ) in those with symptomatic gout and often below $5 \mathrm{mg} / \mathrm{dL}(300 \mu \mathrm{mol} / \mathrm{L})$ in those with features of severe gout such as tophi. ${ }^{94}$

\section{Healthcare and workforce considerations}

People with gout experience shame in seeking treatment for gout ${ }^{96}$ feel stigmatised that their gout diagnosis is associated with perceptions of dietary and alcohol excess and identify they do not have enough information about gout. ${ }^{97}$

Approaches that support patient understanding of gout, strengthen primary care and focus on strong 
relationships between clinician and patient are important in management to enable patients to manage gout and continue urate-lowering therapy. Building health literacy is essential, with one study finding that more than half of patients identified a wish to know more about the cause of gout, treatment goals and long-term treatment. ${ }^{98} \mathrm{~A}$ randomised controlled trial found that nurse-led care for patients that focused on providing individualised information and engaging patients in shared decision-making led to a reduction in gout flares and tophi. ${ }^{92}$ Nurse-led care is associated with greater patient satisfaction and better gout knowledge. ${ }^{99}$ Other models of care, using a protocolised treat-to-target serum urate approach, have also been shown to be effective. A randomised trial of a pharmacist-led service for patients starting allopurinol for gout found that the intervention led to a higher rate of reaching serum urate goal. ${ }^{100}$ A programme providing education and support to patients with the use of community support workers (kaiāwhina) was also effective. ${ }^{101}$

\section{SUMMARY}

The common language definition of gout encompasses key information relevant to gout as determined by a review of the literature, interviews with patients, healthcare workers and stakeholders and consultation with G-CAN members and stakeholders. After the publication of the English-language version, the definition will be available for translation into other languages by G-CAN members, using the approach recommended by the International Society for Pharmacoeconomics and Outcomes Research (ISPOR) Task Force for Translation and Cultural Adaptation. ${ }^{102}$ This concise definition can be used in conversations with the lay public, media, NGOs, funders, healthcare providers and other stakeholders.

\author{
Author affiliations \\ ${ }^{1}$ Department of Medicine, Faculty of Medical and Health Sciences, The University of \\ Auckland, Auckland, New Zealand \\ ${ }^{2}$ Department of Primary Care, Harvard Medical School, Boston, Massachusetts, USA \\ ${ }^{3}$ Division of Rheumatology Allergy and Immunology, Massachusetts General \\ Hospital, Boston, Massachusetts, USA \\ ${ }^{4}$ Global Healthy Living Foundation, Upper Nyack, New York, USA \\ ${ }^{5}$ Department of Rheumatology, Hospital General de México, Ciudad de Mexico, \\ Mexico \\ ${ }^{6}$ Department of Medicine, University of Alabama at Birmingham, Birmingham, \\ Alabama, USA \\ ${ }^{7}$ Medicine Service, Birmingham VA Medical Center, Birmingham, Alabama, USA \\ ${ }^{8}$ Department of Rheumatology, University of California San Diego, La Jolla, \\ California, USA
}

Acknowledgements We thank Rebecca Snyders Hill, Executive Director, Gout, Hyperuricaemia and Crystal-Associated Disease Network (G-CAN), all G-CAN members who provided feedback during the consultation period, and the G-CAN Board members for review and endorsement. We also acknowledge the contributions of participants in the qualitative interviews.

Contributors All authors were part of the steering committee, contributed to the development of the protocol, reviewed all data and the common language definition and approved the final version.

Funding The authors have not declared a specific grant for this research from any funding agency in the public, commercial or not-for-profit sectors.

Competing interests ND reports personal fees and non-financial support from Abbvie, personal fees from Horizon, Janssen, Dyve, Selecta and Arthrosi, grants from Amgen, grants and personal fees from AstraZeneca and personal fees from Hengrui, outside the submitted work. G-CAN is a global gout research consortium, non-profit, supported at arms length by annual funding support from pharma. In the last 36 months, pharma donor support to G-CAN was provided by Horizon, Astra-Zeneca, SOBI, Takeda, CymaBay, Selecta and LG. RT reports other than from G-CAN, during the conduct of the study; personal fees from Astra-Zeneca, SOBI, Horizon, Selecta and grants from Astra-Zeneca, outside the submitted work. JAS has received consultant fees from Crealta/Horizon, Medisys, Fidia, UBM LLC, Trio Health, Medscape, WebMD, Adept Field Solutions, Clinical Care Options, Clearview Healthcare Partners, Putnam Associates, Focus Forward, Navigant Consulting, Spherix, Practice Point Communications, the National Institutes of Health and the American College of Rheumatology. JAS owns stock options in TPT Global Tech, Vaxart Pharmaceuticals and Charlotte's Web Holdings, Inc. JAS previously owned stock options in Amarin, Viking and Moderna Pharmaceuticals. JAS is on the speaker's bureau of Simply Speaking. JAS is a member of the executive of Outcomes Measures in Rheumatology (OMERACT), an organisation that develops outcome measures in rheumatology and receives arms-length funding from 12 companies. JAS serves on the FDA Arthritis Advisory Committee. JAS is the chair of the Veterans Affairs Rheumatology Field Advisory Committee. JAS is the editor and the Director of the University of Alabama at Birmingham (UAB) Cochrane Musculoskeletal Group Satellite Centre on Network Meta-analysis. JAS previously served as a member of the following committees: member, the American College of Rheumatology's (ACR) Annual Meeting. MJB reports grants from Healthwise, a non-profit, outside the submitted work.

Patient consent for publication Not required.

Ethics approval Ethical approval was obtained from the University of Auckland Human Participants Ethics Committee and written consent was obtained prior to the interviews; reference number 024225.

Provenance and peer review Not commissioned; externally peer reviewed.

Data availability statement Data are available upon reasonable request.

Open access This is an open access article distributed in accordance with the Creative Commons Attribution Non Commercial (CC BY-NC 4.0) license, which permits others to distribute, remix, adapt, build upon this work non-commercially, and license their derivative works on different terms, provided the original work is properly cited, appropriate credit is given, any changes made indicated, and the use is non-commercial. See: http://creativecommons.org/licenses/by-nc/4.0/.

\section{ORCID iDs}

Rachel Murdoch http://orcid.org/0000-0001-9842-0721

Jasvinder A Singh http://orcid.org/0000-0003-3485-0006

Nicola Dalbeth http://orcid.org/0000-0003-4632-4476

\section{REFERENCES}

1 Kuo C-F, Grainge MJ, Zhang W, et al. Global epidemiology of gout: prevalence, incidence and risk factors. Nat Rev Rheumatol 2015;11:649-62.

2 Cottrell E, Crabtree V, Edwards JJ, et al. Improvement in the management of gout is vital and overdue: an audit from a UK primary care medical practice. BMC Fam Pract 2013;14:170.

3 Robinson PC, Taylor WJ, Dalbeth N. An observational study of gout prevalence and quality of care in a national Australian general practice population. $J$ Rheumatol 2015;42:1702-7.

4 Singh JA, Hodges JS, Asch SM. Opportunities for improving medication use and monitoring in gout. Ann Rheum Dis 2009;68:1265-70.

5 van der Heijde D, Daikh DI, Betteridge N, et al. Common language description of the term rheumatic and musculoskeletal diseases (RMDs) for use in communication with the lay public, healthcare providers and other stakeholders endorsed by the European League against rheumatism (EULAR) and the American College of rheumatology (ACR). Ann Rheum Dis 2018;77:829-32.

66 Bursill D, Taylor WJ, Terkeltaub R, et al. Gout, hyperuricemia, and Crystal-Associated disease network consensus statement regarding labels and definitions for disease elements in gout. Arthritis Care Res 2019;71:427-34.

7 Bursill D, Taylor WJ, Terkeltaub R, et al. Gout, hyperuricaemia and Crystal-Associated disease network (G-CAN) consensus statement regarding labels and definitions of disease states of gout. Ann Rheum Dis 2019;78:1592-600.

8 Jin Z, Wang D, Zhang H, et al. Incidence trend of five common musculoskeletal disorders from 1990 to 2017 at the global, regional and national level: results from the global burden of disease study 2017. Ann Rheum Dis 2020;79:1014-22. 
99 Xia $\mathrm{Y}, \mathrm{Wu} \mathrm{Q}$, Wang $\mathrm{H}$, et al. Global, regional and national burden of gout, 1990-2017: a systematic analysis of the global burden of disease study. Rheumatology 2020;59:1529-38.

10 Safiri S, Kolahi A-A, Cross M, et al. Prevalence, incidence, and years lived with disability due to gout and its attributable risk factors for 195 countries and territories 1990-2017: a systematic analysis of the global burden of disease study 2017. Arthritis Rheumatol 2020;72:1916-27.

11 Dalbeth N, Choi HK, Joosten LAB, et al. Gout. Nat Rev Dis Primers 2019:5:69.

12 Hui M, Carr A, Cameron S, et al. The British Society for rheumatology guideline for the management of gout. Rheumatology 2017; 56:e1-20.

13 Chen-Xu M, Yokose C, Rai SK, et al. Contemporary prevalence of gout and hyperuricemia in the United States and Decadal trends: the National health and nutrition examination survey, 2007-2016. Arthritis Rheumatol 2019;71:991-9.

14 Kuo C-F, Grainge MJ, Mallen C, et al. Rising burden of gout in the UK but continuing suboptimal management: a nationwide population study. Ann Rheum Dis 2015;74:661-7.

15 Richette P, Doherty M, Pascual E, et al. 2018 updated European League against rheumatism evidence-based recommendations for the diagnosis of gout. Ann Rheum Dis 2020;79:31-8.

16 Zhu Y, Pandya BJ, Choi HK. Prevalence of gout and hyperuricemia in the US general population: the National health and nutrition examination survey 2007-2008. Arthritis Rheum 2011;63:3136-41.

17 Wallace KL, Riedel AA, Joseph-Ridge N, et al. Increasing prevalence of gout and hyperuricemia over 10 years among older adults in a managed care population. $J$ Rheumatol 2004;31:1582-7.

18 McDougall C, Hurd K, Barnabe C. Systematic review of rheumatic disease epidemiology in the Indigenous populations of Canada, the United States, Australia, and New Zealand. Semin Arthritis Rheum 2017;46:675-86.

19 Tu F-Y, Lin G-T, Lee S-S, et al. Prevalence of gout with comorbidity aggregations in southern Taiwan. Joint Bone Spine 2015;82:45-51.

20 Health Quality and Safety Commission. Atlas of healthcare variation, 2020

21 Chang SJ, Ko YC, Wang TN, et al. High prevalence of gout and related risk factors in Taiwan's aborigines. J Rheumatol 1997;24:1364-9

22 Dalbeth N, Stamp L. Hyperuricaemia and gout: time for a new staging system? Ann Rheum Dis 2014;73:1598-600.

23 Fox IH. Metabolic basis for disorders of purine nucleotide degradation. Metabolism 1981;30:616-34.

24 Sorensen LB. Role of the intestinal tract in the elimination of uric acid. Arthritis Rheum 1965;8:694-706.

25 Loeb JN. The influence of temperature on the solubility of monosodium urate. Arthritis Rheum 1972;15:189-92.

26 Martinon F, Pétrilli V, Mayor A, et al. Gout-associated uric acid crystals activate the NALP3 inflammasome. Nature 2006;440:237-41.

27 Pascual E, Batlle-Gualda E, Martínez A, et al. Synovial fluid analysis for diagnosis of intercritical gout. Ann Intern Med 1999;131:756-9.

28 Dalbeth N, Clark B, Gregory K, et al. Mechanisms of bone erosion in gout: a quantitative analysis using plain radiography and computed tomography. Ann Rheum Dis 2009;68:1290-5.

29 Lindsay K, Gow P, Vanderpyl J, et al. The experience and impact of living with gout: a study of men with chronic gout using a qualitative grounded theory approach. $J$ Clin Rheumatol 2011;17:1-6.

30 Neogi T, Jansen TLTA, Dalbeth N, et al. 2015 gout classification criteria: an American College of Rheumatology/European League against rheumatism collaborative initiative. Ann Rheum Dis 2015;74:1789-98.

31 Raddatz DA, Mahowald ML, Bilka PJ. Acute polyarticular gout. Ann Rheum Dis 1983;42:117-22.

32 Teoh N, Gamble GD, Horne A, et al. The challenges of gout flare reporting: mapping flares during a randomized controlled trial. $B M C$ Rheumatol 2019;3:27.

33 Janssens HJEM, Janssen M, van de Lisdonk EH, et al. Use of oral prednisolone or naproxen for the treatment of gout arthritis: a double-blind, randomised equivalence trial. The Lancet 2008:371:1854-60.

34 Singh JA. Self-Reported sleep quality and sleep disorders in people with physician-diagnosed gout: an Internet cross-sectional survey. Arthritis Res Ther 2019;21:36.

35 Blagojevic-Bucknall M, Mallen C, Muller S, et al. The risk of gout among patients with sleep apnea: a matched cohort study. Arthritis Rheumatol 2019;71:154-60.
36 Zhang Y, Peloquin CE, Dubreuil M, et al. Sleep apnea and the risk of incident gout: a population-based, body mass Index-Matched cohort study. Arthritis Rheumatol 2015;67:3298-302.

37 Singh JA, Cleveland JD. Gout and the risk of incident obstructive sleep apnea in adults 65 years or older: an observational study. $J$ Clin Sleep Med 2018;14:1521-7.

38 Sigurdardottir V, Drivelegka P, Svärd A, et al. Work disability in gout: a population-based case-control study. Ann Rheum Dis 2018;77:399-404.

39 Rai SK, Burns LC, De Vera MA, et al. The economic burden of gout: a systematic review. Semin Arthritis Rheum 2015;45:75-80.

40 Perez-Ruiz F, Calabozo M, Erauskin GG, et al. Renal underexcretion of uric acid is present in patients with apparent high urinary uric acid output. Arthritis Rheum 2002;47:610-3.

41 Köttgen A, Albrecht E, Teumer A, et al. Genome-Wide association analyses identify 18 new loci associated with serum urate concentrations. Nat Genet 2013:45:145-54.

42 Okada Y, Sim X, Go MJ, et al. Meta-Analysis identifies multiple loci associated with kidney function-related traits in East Asian populations. Nat Genet 2012:44:904-9.

43 Matsuo H, Yamamoto K, Nakaoka H, et al. Genome-Wide association study of clinically defined gout identifies multiple risk loci and its association with clinical subtypes. Ann Rheum Dis 2016;75:652-9.

44 Noordzij TC, Leunissen KM, Van Hooff JP. Renal handling of urate and the incidence of gouty arthritis during cyclosporine and diuretic use. Transplantation 1991;52:64-6.

45 McAdams-DeMarco MA, Law A, Maynard JW, et al. Risk factors for incident hyperuricemia during mid-adulthood in African American and white men and women enrolled in the ARIC cohort study. BMC Musculoskelet Disord 2013:14:347.

46 Narang RK, Vincent Z, Phipps-Green A, et al. Population-specific factors associated with fractional excretion of uric acid. Arthritis Res Ther 2019;21:234.

47 Yamashita S, Matsuzawa Y, Tokunaga K, et al. Studies on the impaired metabolism of uric acid in obese subjects: marked reduction of renal urate excretion and its improvement by a lowcalorie diet. Int J Obes 1986;10:255-64

48 Emmerson BT. Alteration of urate metabolism by weight reduction. Aust N Z J Med 1973;3:410-2.

49 Mandal AK, Mount DB. The molecular physiology of uric acid homeostasis. Annu Rev Physiol 2015;77:323-45.

50 Isenberg DA, Shoenfeld Y. The rheumatologic complications of hematologic disorders. Semin Arthritis Rheum 1983;12:348-58.

51 Ichida K, Matsuo H, Takada T, et al. Decreased extra-renal urate excretion is a common cause of hyperuricemia. Nat Commun 2012;3:764

52 Major TJ, Topless RK, Dalbeth N, et al. Evaluation of the diet wide contribution to serum urate levels: meta-analysis of population based cohorts. BMJ 2018;363:k3951.

53 Tin A, Marten J, Halperin Kuhns VL, et al. Target genes, variants, tissues and transcriptional pathways influencing human serum urate levels. Nat Genet 2019;51:1459-74.

54 Nakayama A, Nakaoka H, Yamamoto K, et al. Gwas of clinically defined gout and subtypes identifies multiple susceptibility loci that include urate transporter genes. Ann Rheum Dis 2017;76:869-77.

55 Dehghan A, Köttgen A, Yang Q, et al. Association of three genetic loci with uric acid concentration and risk of gout: a genome-wide association study. Lancet 2008;372:1953-61.

56 Modan M, Halkin H, Fuchs Z, et al. Hyperinsulinemia--a link between glucose intolerance, obesity, hypertension, dyslipoproteinemia, elevated serum uric acid and internal cation imbalance. Diabete Metab 1987;13:375-80.

57 Facchini F, Chen YD, Hollenbeck CB, et al. Relationship between resistance to insulin-mediated glucose uptake, urinary uric acid clearance, and plasma uric acid concentration. JAMA 1991;266:3008-11.

58 Palmer TM, Nordestgaard BG, Benn M, et al. Association of plasma uric acid with ischaemic heart disease and blood pressure: Mendelian randomisation analysis of two large cohorts. BMJ 2013;347:f4262.

59 Lyngdoh T, Vuistiner P, Marques-Vidal P, et al. Serum uric acid and adiposity: deciphering causality using a bidirectional Mendelian randomization approach. PLoS One 2012;7:e39321.

60 Oikonen M, Wendelin-Saarenhovi M, Lyytikäinen L-P, et al. Associations between serum uric acid and markers of subclinical atherosclerosis in young adults. the cardiovascular risk in young Finns study. Atherosclerosis 2012;223:497-503.

61 Maglio C, Peltonen M, Neovius M, et al. Effects of bariatric surgery on gout incidence in the Swedish obese subjects study: a non- 
randomised, prospective, controlled intervention trial. Ann Rheum Dis 2017:76:688-93.

62 Dalbeth N, Chen P, White M, et al. Impact of bariatric surgery on serum urate targets in people with morbid obesity and diabetes: a prospective longitudinal study. Ann Rheum Dis 2014;73:797-802.

63 Nielsen SM, Bartels EM, Henriksen M, et al. Weight loss for overweight and obese individuals with gout: a systematic review of longitudinal studies. Ann Rheum Dis 2017;76:1870-82.

64 Yokose C, McCormick N, Rai SK, et al. Effects of low-fat, Mediterranean, or low-carbohydrate weight loss diets on serum urate and cardiometabolic risk factors: a secondary analysis of the dietary intervention randomized controlled trial (direct). Diabetes Care 2020;43:2812-20.

65 Dessein PH, Stanwix AE, Joffe BI. Cardiovascular risk in rheumatoid arthritis versus osteoarthritis: acute phase response related decreased insulin sensitivity and high-density lipoprotein cholesterol as well as clustering of metabolic syndrome features in rheumatoid arthritis. Arthritis Res 2002;4:R5.

66 Zhu Y, Zhang Y, Choi HK. The serum urate-lowering impact of weight loss among men with a high cardiovascular risk profile: the multiple risk factor intervention trial. Rheumatology 2010;49:2391-9.

67 Maynard JW, McAdams DeMarco MA, Baer AN, et al. Incident gout in women and association with obesity in the Atherosclerosis risk in communities (ARIC) study. Am J Med 2012;125:717.e9-17.

68 Krishnan M, Major TJ, Topless RK, et al. Discordant association of the CREBRF rs373863828 a allele with increased BMI and protection from type 2 diabetes in Māori and Pacific (Polynesian) people living in Aotearoa/New Zealand. Diabetologia 2018;61:1603-13.

69 Choi HK, Liu S, Curhan G. Intake of purine-rich foods, protein, and dairy products and relationship to serum levels of uric acid: the third National health and nutrition examination survey. Arthritis Rheum 2005:52:283-9.

70 Choi HK, Curhan G. Beer, liquor, and wine consumption and serum uric acid level: the third National health and nutrition examination survey. Arthritis Rheum 2004;51:1023-9.

71 Choi HK, Atkinson K, Karlson EW, et al. Purine-Rich foods, dairy and protein intake, and the risk of gout in men. $N$ Engl J Med 2004;350:1093-103.

72 Choi HK, Atkinson K, Karlson EW, et al. Alcohol intake and risk of incident gout in men: a prospective study. Lancet 2004;363:1277-81

73 Zhang Y, Chen $\mathrm{C}$, Choi $\mathrm{H}$, et al. Purine-Rich foods intake and recurrent gout attacks. Ann Rheum Dis 2012;71:1448-53.

74 Zhang Y, Woods R, Chaisson CE, et al. Alcohol consumption as a trigger of recurrent gout attacks. Am J Med 2006;119:800.e11-16.

75 Clifford AJ, Riumallo JA, Young VR, et al. Effect of oral purines on serum and urinary uric acid of normal, hyperuricemic and gouty humans. J Nutr 1976;106:428-34.

76 Zöllner N, Griebsch A. Diet and gout. Adv Exp Med Biol 1974:41:435-42.

77 Juraschek SP, Gelber AC, Choi HK, et al. Effects of the dietary approaches to stop hypertension (DASH) diet and sodium intake on serum uric acid. Arthritis Rheumatol 2016;68:3002-9.

78 Juraschek SP, Yokose C, McCormick N, et al. Effects of dietary patterns on serum urate: results from the DASH randomized trial. Arthritis Rheumatol. In Press 2020. doi:10.1002/art.41614. [Epub ahead of print: 08 Dec 2020].

79 Belanger MJ WC, Mukamal KJ, et al. Effects of dietary macronutrients on serum urate: results from the OmniHeart trial. Am J Clin Nutr 2020:nqaa424.

80 Rai SK, Fung TT, Lu N, et al. The dietary approaches to stop hypertension (DASH) diet, Western diet, and risk of gout in men: prospective cohort study. BMJ 2017;357:j1794.

81 Choi HK, Ford ES, Li C, et al. Prevalence of the metabolic syndrome in patients with gout: the third National health and nutrition examination survey. Arthritis Rheum 2007;57:109-15.

82 Zhu Y, Pandya BJ, Choi HK. Comorbidities of gout and hyperuricemia in the US general population: NHANES 2007-2008. Am J Med 2012;125:e671:679-87.
83 Fisher MC, Rai SK, Lu N, et al. The unclosing premature mortality gap in gout: a general population-based study. Ann Rheum Dis 2017;76:1289-94

84 Roughley MJ, Belcher J, Mallen CD, et al. Gout and risk of chronic kidney disease and nephrolithiasis: meta-analysis of observational studies. Arthritis Res Ther 2015;17:90.

85 FitzGerald JD, Dalbeth N, Mikuls T. 2020 American College of rheumatology guideline for the management of gout. Arthritis Rheumatol 2020.

86 Roddy E, Clarkson K, Blagojevic-Bucknall M, et al. Open-Label randomised pragmatic trial (contact) comparing naproxen and lowdose colchicine for the treatment of gout flares in primary care. Ann Rheum Dis 2020;79:276-84.

87 Schlesinger N, Detry MA, Holland BK, et al. Local ice therapy during bouts of acute gouty arthritis. J Rheumatol 2002;29:331-4.

88 Schlesinger N, Alten RE, Bardin T, et al. Canakinumab for acute gouty arthritis in patients with limited treatment options: results from two randomised, multicentre, active-controlled, double-blind trials and their initial extensions. Ann Rheum Dis 2012;71:1839-48.

89 Pascual E, Sivera F. Time required for disappearance of urate crystals from synovial fluid after successful hypouricaemic treatment relates to the duration of gout. Ann Rheum Dis 2007;66:1056-8.

90 Perez-Ruiz F, Calabozo M, Pijoan Jl, et al. Effect of urate-lowering therapy on the velocity of size reduction of tophi in chronic gout. Arthritis Rheum 2002;47:356-60.

91 Dalbeth N, Saag KG, Palmer WE, et al. Effects of febuxostat in early gout: a randomized, double-blind, placebo-controlled study. Arthritis Rheumatol 2017;69:2386-95.

92 Doherty M, Jenkins W, Richardson $\mathrm{H}$, et al. Efficacy and cost-effectiveness of nurse-led care involving education and engagement of patients and a treat-to-target urate-lowering strategy versus usual care for gout: a randomised controlled trial. Lancet 2018;392:1403-12.

93 Dalbeth N, Billington K, Doyle A, et al. Effects of allopurinol dose escalation on bone erosion and urate volume in gout: a dual-energy computed tomography imaging study within a randomized, controlled trial. Arthritis Rheumatol 2019;71:1739-46.

94 Richette P, Doherty M, Pascual E, et al. 2016 updated EULAR evidence-based recommendations for the management of gout. Ann Rheum Dis 2017;76:29-42.

$95 \mathrm{Kim}$ SC, Neogi T, Kim E, et al. Trends in Utilization of UrateLowering Therapies Following the US Food and Drug Administration's Boxed Warning on Febuxostat. Arthritis Rheumatol 2021;73:542-3.

96 Kong DCH, Sturgiss EA, Dorai Raj AK, et al. What factors contribute to uncontrolled gout and hospital admission? A qualitative study of inpatients and their primary care practitioners. BMJ Open 2019;9:e033726.

97 Vaccher S, Kannangara DRW, Baysari MT, et al. Barriers to care in gout: from prescriber to patient. J Rheumatol 2016;43:144-9.

98 van Onna M, Hinsenveld E, de Vries $\mathrm{H}$, et al. Health literacy in patients dealing with gout: a qualitative study. Clin Rheumatol 2015;34:1599-603.

99 Fuller A, Jenkins W, Doherty M, et al. Nurse-Led care is preferred over GP-led care of gout and improves gout outcomes: results of Nottingham gout treatment trial follow-up study. Rheumatology 2020;59:575-9.

100 Mikuls TR, Cheetham TC, Levy GD, et al. Adherence and outcomes with urate-lowering therapy: a Site-Randomized trial. Am J Med 2019;132:354-61.

101 Lawrence A, Scott S, Saparelli F, et al. Facilitating equitable prevention and management of gout for Māori in Northland, New Zealand, through a collaborative primary care approach. J Prim Health Care 2019;11:117-27.

102 Wild D, Grove A, Martin M, et al. Principles of good practice for the translation and cultural adaptation process for patient-reported outcomes (pro) measures: report of the ISPOR Task force for translation and cultural adaptation. Value Health 2005;8:94-104 